\title{
TRANSTORNO DA ACUMULAÇÃO NO DISTRITO DE SAÚDE LAPA/PINHEIROS, NO MUNICÍPIO DE SÃO PAULO (SP) ENTRE 2016 E 2019
}

\author{
ACCUMULATION DISORDER IN THE LAPA / PINHEIROS HEALTH DISTRICT, \\ IN THE CITY OF SÃO PAULO (SP) BETWEEN 2016 AND 2019
}

\author{
TRASTORNO DE ACUMULACIÓN EN EL DISTRITO DE SALUD DE LAPA / \\ PINHEIROS, EN LA CIUDAD DE SÃO PAULO (SP) ENTRE 2016 Y 2019
}

\author{
Mayne Medeiros Maia ${ }^{1}$ \\ Edna Patrícia Cupertino ${ }^{2}$ \\ Cesar Oscar Polachini ${ }^{3}$ \\ Viviane Cristina Mendonça Martins ${ }^{4}$ \\ Leila Maria Rissi Caverni ${ }^{5}$
}

RESUMO: Estudo analisa 49 casos de pessoas em Situação de Acumulação (SA), residentes nos distritos administrativos (D.A.) da Lapa e de Pinheiros do município de São Paulo, encaminhados ao serviço de Vigilância Ambiental da Supervisão Técnica de Saúde da Lapa/Pinheiros, entre os anos de 2016 a 2019. Os parâmetros analisados foram: Raça / Cor / Etnia, Ocupação / Forma de sustento, Situação do imóvel de moradia, Faixa etária e sexo, Tipo de material acumulado, Número de ações realizadas e quantidade de material removido no período. Os resultados mostram predomínio de indivíduos da raça branca, inativos e, residentes em imóvel próprio. Discreta maioria de casos pertencentes ao sexo masculino, em relação ao sexo feminino. Maior parte dos acometidos acumulam objetos inanimados em comparação com os que acumulam animais. $\mathrm{O}$ volume de material removido, com apoio institucional foi consideravelmente maior quando comparado ao desfazimento deixado a critério do próprio indivíduo. O conhecimento mais detalhado do agravo,

\footnotetext{
I Bacharel em Serviço Social pela PUC-SP, Especialista em Dependência Química pela UNIFESP, Assistente Social responsável pelo Serviço de Atenção às Pessoas em Situação de Acumulação da Unidade de Vigilância em Saúde - UVIS Lapa Pinheiros/Vigilância Ambiental, da Secretaria da Saúde do Município de São Paulo.E-mail: mayne@uol.com.br.

2 Bacharel em Serviço Social pela Faculdade Anhanguera/São Paulo, Especialista em Gerontologia pela UNINOVE. Agente de Saúde Ambiental/Endemias UVIS Lapa Pinheiros/Vigilância Ambiental, da Secretaria da Saúde do Município de São Paulo.

${ }_{3}^{3}$ Graduado pela Faculdade de Ciências Médicas da Santa Casa de São Paulo, Mestre pelo Programa de Pós-Graduação em Ciências, da Coordenação dos Institutos de Pesquisa da Secretaria de Estado Saúde de São Paulo em 2004. Médico na UVIS Lapa Pinheiros/Vigilância Ambiental, da Secretaria da Saúde do Município de São Paulo.

4 Bacharel em Enfermagem pelo Centro Universitário Campus de Andrade, Curitiba - PR. Coordenadora da Vigilância Ambiental Lapa/Pinheiros - UVIS Lapa Pinheiros/Vigilância Ambiental, da Secretaria da Saúde do Município de São Paulo. (2017-2020).

5 Graduada em Enfermagem pela Universidade de São Paulo em 1976. Doutora em Ciencias pela Universidade de São Paulo-Unifesp. Vigilância Ambiental Lapa / Pinheiros da Secretaria Municipal da Saúde do Município de São Paulo
} 
possibilita intervenções a partir da identificação dos casos, na promoção e cuidado à saúde integral desse segmento populacional e oportuniza modificações da realidade ambiental de forma antecipada.

Palavras-chave: Transtorno da Acumulação. Síndrome de Diógenes. Acumulação obsessiva. Saúde Pública.

ABSTRACT: This study analyzes 49 cases of people with hoarding disorder residing in the Administrative Districts of Lapa and Pinheiros both located in the municipality of São Paulo and under surveillance of the Environmental Surveillance Department of Technical Health Supervision of Lapa/Pinheiros, between the years 2016 and 2019. The analysis parameters were: race/ color/ethnicity, occupation/ livelihood, housing issues, age, gender, types of collected objects, number of actions performed by public services and amount of material removed in the period. The results show a majority of white individuals, with an inactive lifestyle and residing in their own properties. Discrete majority of cases belonging to the male sex, in relation to the female sex. Most affected people accumulate inanimate objects in comparison to animal accumulators. The volume of material removed, with institutional support, was considerably higher when compared to the scrap left to the individual's discretion. Amore detailed knowledge of the disease brings together possibilities for intervention based on the identification of cases, in the promotion and care for comprehensive health of this population segment and allows for changes in the environment reality in advance.

Keywords: Hoarding Disorder. Diogenes Syndrome. Obsessive accumulation.Public Health.

RESUMEN: El estudio analiza 49 casos de personas en situación de acumulación (SA) que residen en los Distrito Administrativo (DA) de Lapa y Pinheiros en el municipio de São Paulo, referidos al Servicio de Vigilancia Ambiental de la Supervisión Técnica de Salud de Lapa / Pinheiros, entre los años de 2016 a 2019. Los parámetros analizados fueron: raza / color / etnia, ocupación / forma de vida, situación de la vivienda, grupo de edad y sexo, tipo de material acumulado, número de acciones realizadas y cantidad de material eliminado en el período. Los resultados muestran que la mayoría de las personas pertenecientes a la raza blanca, inactivas y que residen en su propia propiedad.La mayoria discreta de los casos pertenecientes al sexo masculino em relacion com el sexo feminino. La mayor parte de las personas afectadas acumulan objetos inanimados em comparación com los acumuladores de animales. El volume de material eliminado com apoyo institucional fue considerablemente mayor em comparación com la chatarra dejada a discreción del individuo.El conocimento $\mathrm{m}^{\prime}$ as detallado de la enfermedad permite intervenciones basadas em la identificación de casos, em la promoción y atención de la salud integral de este segmento de la población y permite en la realidade ambiental de antemano. 
Palabras-clave: Trastorno de acumulación. Síndrome de Diógenes. acumulación obsessiva. Salud Pública.

\section{INTRODUÇÃO}

Por volta de dois anos de idade o conceito de posse de objetos é estabelecido como parte de nós mesmos, podendo fincar relações intensas com um objeto em particular. $\mathrm{Na}$ adolescência podem se transformar em amparo para o self, e com o passar do tempo vão se tornando reflexo do que somos e na velhice, nossas posses são memórias da vida, de significados, uma fonte de conforto e auxílio à reflexão. Pode se afirmar que nossos relacionamentos interpessoais, de alguma forma, são reflexo e parte, das nossas relações com os objetos (STUMPF, 2018).

Freud no início do século 20, relacionou o "caráter anal" com a questão da acumulação: "recusa em dar", e o "desejo de reunir, colecionar e acumular". Jones em I9I2 sugeriu que dinheiro, livros, tempo, comida e outros objetos seriam equivalentes fecais do caráter anal.

O Transtorno da Acumulação (TA) é uma terminologia nova no DSM-5 (Manual Diagnóstico e Estatístico de Transtornos Mentais, 2013). Anteriormente era listado como um critério possível para o transtorno da personalidade obsessivo compulsiva, mas evidências indicam que a acumulação disfuncional existe frequentemente, sem um diagnóstico concomitante que explique o comportamento (BARNHILL, 2015).

O diagnóstico de TA se refere a indivíduos que acumulam objetos, ou animais, experimentam sofrimento e prejuízo pela dificuldade de se desfazerem ou se separarem de determinados bens, conservam a percepção de que necessitam guardar esses itens, apresentando angústia frente à ideia de descartá-los (ARAUJO, A.2013; RESENDE,2015; STUMPF,2018). Da desorganização com consequências na rotina e segurança do ambiente doméstico, decorrem prejuízos em diversos aspectos da vida cotidiana, no âmbito social e ocupacional, dificultando o convívio em geral (ARAUJO, E.2015; CORREIA,2016; MELEIRO,2018; SCHMIDT,2014; STUMPF,2018).

Descuido com cuidados e higiene pessoal, isolamento e abandono do cuidado ambiental podem acompanhar o quadro. A falta de pudor visível através da quebra de condutas sociais básicas também aponta para o transtorno (ARAUJO, A.2013).

Os acometidos pelo transtorno temem constrangimentos ou estigmatização, escondem suas obsessões e rituais, como forma de camuflagem social, evitando sanções ao seu comportamento. Podem se isolar e, frequentemente, são refratários à visitação em suas residências (CORREIA,2016; HENRIQUES,2019).

As causas do TA são desconhecidas. Algumas hipóteses para a etiologia dessa psicopatologia são: componente genético, traumas na vida pregressa, transtorno de 
personalidade (isolamento, desconfiança, agressividade, labilidade emocional e tendência a distorcer a realidade), demência do lobo cerebral central, transtorno obsessivo compulsivo, problema psiquiátrico associado ao ato de colecionar ( SCHMIDT,2014; HENRIQUES,2019; LERVOLINO,2009; STUMPF,2018). O desencadeamento da patologia sinaliza, em alguns relatos, associação com estressores biológicos, psicológicos, sociais ou associados a idade ou ao uso do álcool e drogas (HENRIQUES,2019; SCHMIDT,2014).

Lervolino et al. (2009), em um estudo realizado com gêmeos, concluíram que $50 \%$ da questão genética é corresponsável pela etiologia do transtorno, sendo que mais de $80 \%$ dos indivíduos que acumulam, referem presença de TA no histórico familiar. Contudo, outros relatam a presença de alguns eventos de infância em comum nos sujeitos com comportamento de acumular, como uso da disciplina física e presença de transtornos psiquiátricos por parte dos pais (STUMPF2or8). Além disso, indivíduos com TA que vivenciaram situações de trauma na infância desenvolvem seus sintomas em idades mais precoces quando comparados a pacientes com o mesmo diagnóstico (LERVOLINO,2009; SCHMIDT,2014; STUMPF,2018).

Essa disfunção pode estar presente desde a infância ou adolescência, indicando que os sintomas, geralmente, intensificam-se a partir da meia-idade tornando-se mais graves com o passar do tempo (GARGIULO,2019). Idosos com esse comportamento constituem uma população de alta vulnerabilidade, apresentando comprometimento das atividades de vida diária, com taxa de mortalidade de aproximadamente 50\% em 5 anos de seguimento, mostrando a relevância clínica do transtorno. Ressalta-se que, em sua grande maioria, indivíduos com esse transtorno são tardiamente identificados, entrando no sistema público de saúde quando já estão acometidos por outras comorbidades associadas (HENRIQUES,2019).

Mesmo em idosos com histórico de tratamento psiquiátrico o TA é usualmente subdiagnosticado e pouco tratado. Dessa forma, é imprescindível que os profissionais de saúde, especialmente aqueles que atendem idosos, conheçam os sintomas e façam a avaliação adequada do agravo (STUMPF,2018).

Alguns autores utilizam o termo Síndrome de Diógenes, para ser referir ao TA. Essa síndrome é caracterizada por pessoas com comportamento paranoico que negligenciam a higiene pessoal e de sua moradia, seguindo filosofia do desapego a bens materiais. Quando os animais são objeto do acúmulo, o termo Síndrome de Noé é mencionado por alguns estudiosos. (CALDERON,2019; LERVOLINO, 2009; RESENDE,2015; UFMG,2016).

Estudos de prevalência na população apresentam grande variação: Massachusetts, nos Estados Unidos, com 26 acumuladores por Ioo.ooo habitantes, Alemanha com 4,6\% e Itália com $6,0 \%$ da população em geral. Na Austrália encontrado uma prevalência de I por r.ooo habitantes (HENRIQUES,2019). No Reino Unido, foi de $1,5 \%$ em ambos os sexos, sendo o TA mais prevalente em adultos 
mais velhos. Estudo na Holanda mostrou a prevalência de TA de 2,12\% em ambos os sexos, com aumentos lineares em torno de $20 \%$ a cada 5 anos. Estudo conduzido em Curitiba (PR) o comportamento acumulador ficou em uma taxa de 6,45 acumuladores/ıoo.ooo habitantes. Estimou-se com esse trabalho, a existência de I caso de acumulação compulsiva para cada 15.503 habitantes; 7.390 homens, 8.113 mulheres (STUMPF,2018). Acredita-se que entre $2 \%$ a $6 \%$ da população em geral, apresentam esse transtorno (BERNILL,2015; GARGIULO,2019; STUMPF,2018).

Em relação ao acúmulo de animais, na América do Norte, o perfil das pessoas que acumulam animais é de mulheres idosas, socialmente desfavorecidas, que vivem sozinhas (ARAUJO, E.2015; TOMMASO,2017), chegando a uma proporção estimada de o,8o casos a cada roo.ooo habitantes. No Brasil primeiro estudo, em Curitiba em 2017 mostrou uma proporção de 3,71 casos a cada Ioo.ooo habitantes na cidade. Segundo GARGIULO (2019), o termo "acumulação" foi utilizado cientificamente em humanos , em 1966.

$\mathrm{Na}$ acumulação excessiva de animais, a pessoa acumula animais que estima. Costumam ser bastante apegadas a eles e não querem abandoná-los. Às vezes há caracterização de maus tratos por não conseguir alimentá-los nem prestar atendimento veterinário adequados (ARAUJO, E.2015; CALDERON,2019; GARGIULO,2019; STUMPF,2018). No entanto, muitas pessoas com esse transtorno não reconhecem o descuido e o sofrimento imputado a essas criaturas (CALDERON,2019; HENRIQUES,2019; LERVOLINO,2009; RODRIGUES,2019). Rodrigues (2019) em revisão da literatura "indica que a proporção entre os sexos é relativamente uniforme para os casos do transtorno de acumulação de objetos, enquanto casos de acumulação de animais são predominantemente relacionados ao sexo feminino".

O acúmulo de animais agrega riscos potenciais; tais como ambientes insalubres consequentes à exposição a elevados teores de amônia urinária, podendo acarretar irritação das mucosas ocular e respiratória; ruído excessivo por latidos ou miados, odor no entorno, e proliferação de insetos e roedores (GARCIA,2019; SCHMIDT,2014; HENRIQUES,2019, TOMMASO,2017).

Com a desorganização, há incremento do risco de incêndios, soterramentos pelos objetos acumulados, não sendo incomum a infestação por animais sinantrópicos na residência. Agrava-se a insegurança no caso de idosos, com riscos adicionais de quedas e de higiene precária (SCHMIDT,2014; TOMMASO,2017). Algumas pessoas percebem que a acumulação excessiva é um problema, mas muitas não, com pouco interesse em receber tratamento e conter a compulsão. Sem tratamento, os sintomas normalmente persistem durante toda a vida, com pouca ou nenhuma alteração no quadro nosológico (GARGIULO,2org; HENRIQUES,2019; STUMPF,2018).

Evidentemente alguns "estilos de vida" são potencialmente perigosos para o indivíduo e ou para os que o cercam, como o transtorno em estudo. É essencial não 
perder de vista, que ações culpabilizantes, limitadas e, de efetividade restrita devam ser evitadas. Devemos cuidar para não ditar comportamentos do bom viver, que se limitam a prescrever atitudes independentes dos condicionamentos sociais, econômicos e culturais e da biografia de cada indivíduo (CASTIEL,2oro).

O agravo é complexo, conhecido pela gestão dos municípios há algum tempo, e de difícil abordagem na promoção e no cuidado à saúde. A visibilidade do fenômeno, predominantemente urbano, alarga o olhar dos profissionais de diversas áreas, abrindo possibilidades de explicitação e intervenção singulares a esse problema de saúde pública.

Os relatos com enfoque em saúde pública, a respeito do TA no Brasil não são de grande extensão (RESENDE,2015; SCHMIDT ,2014), retardando políticas públicas voltadas a esse segmento populacional. O objetivo deste levantamento visa colaborar na compreensão da morbidade e na discussão de ações de promoção interdisciplinar da Saúde e de Vigilância em Saúde sobre o tema.

Em 28 de dezembro de 2016, Decreto Municipal № 57.570, institui a Política Municipal de Atenção Integral às Pessoas em Situação de Acumulação no município de São Paulo. Foram criados Comitês Regionais de Atenção Integral às Pessoas em Situação de Acumulação (CRASA) em todas as Subprefeituras do município de São Paulo.

Apesar de o Decreto Municipal se referir a " pessoas em situação de acumulação" neste relato, optou-se por utilizar o termo - "Transtorno da Acumulação" - por constar no Manual Diagnóstico e Estatístico de Transtornos Mentais da Associação Psiquiátrica Americana (DSM-5).O DSM-5 é um dispositivo oficial para os diagnósticos psiquiátricos nos Estados Unidos, globalmente utilizado, e tem influência sobre a Classificação Internacional de Transtornos Mentais da Organização Mundial de Saúde (OMS).

Além de facilitar a utilização por profissionais da área clínica e pesquisa, o DSM configura-se como fonte de referência cientificamente embasada para padronizar a linguagem e facilitar o diálogo entre diferentes áreas.

\section{MATERIAL E MÉTODOS}

O Serviço de Vigilância Ambiental Lapa/Pinheiros, constituiu equipe para acompanhar pessoas em situação de acumulação, tendo em sua composição um técnico do Serviço Social, e dois agentes de Saúde/ Endemias, devidamente capacitados para a função.

As solicitações de intervenção dos casos ocorrem pelo sistema local de saúde, por meio de cidadãos que operam denúncias pelo serviço de atendimento ao cidadão ( $\mathrm{SAC}_{156}$ ), outros serviços de saúde e menos frequentemente por demandas judiciais. 
Confirmada a procedência da demanda, inicia-se o planejamento / estratégia de contatos e vistorias, com a investigação e acompanhamento do caso. É priorizado o acompanhamento, do caso, em conjunto com a atenção básica que é a gestora do caso segundo o decreto municipal $\mathrm{n}$ - 57.570/2016. O estudo descritivo atual refere-se aos casos investigados no referido período.

\section{RESULTADOS}

A região das subprefeituras da Lapa e de Pinheiros, está localizada na zona oeste do município de São Paulo, possui ro Distritos Administrativos (DA); sendo seis destes distritos, na Subprefeitura Lapa, e quatro na Subprefeitura de Pinheiros, com uma população estimada de 615.549 habitantes em 2019 (Fundação Seade). Em 2010, o Índice de Desenvolvimento Humano (IDH), que tem como componentes básicos: renda, longevidade e educação, no DA de Pinheiros foi de 0,942 e na Lapa foi de o,906; mostrando um satisfatório índice de desenvolvimento econômico e social em ambas as subprefeituras (IPEA).

A figura I mostra a distribuição do TA, entre os anos de 2016 e 2019, segundo as categorias de raça/cor/etnia, na qual se observa que a maioria dos acometidos pelo agravo são brancos $(80,0 \%)$, com I0\% pardos e apenas $2 \%$ pretos. Não observado nenhum representante da raça amarela nem da etnia indígena na atual casuístic

Figura I - Distribuição percentual dos casos de transtorno da acumulação na Subprefeitura regional da Lapa e na Subprefeitura de Pinheiros, do município de São Paulo, entre 2016 e 2019, segundo as categorias, utilizadas pelo IBGE, de raça/cor/etnia.

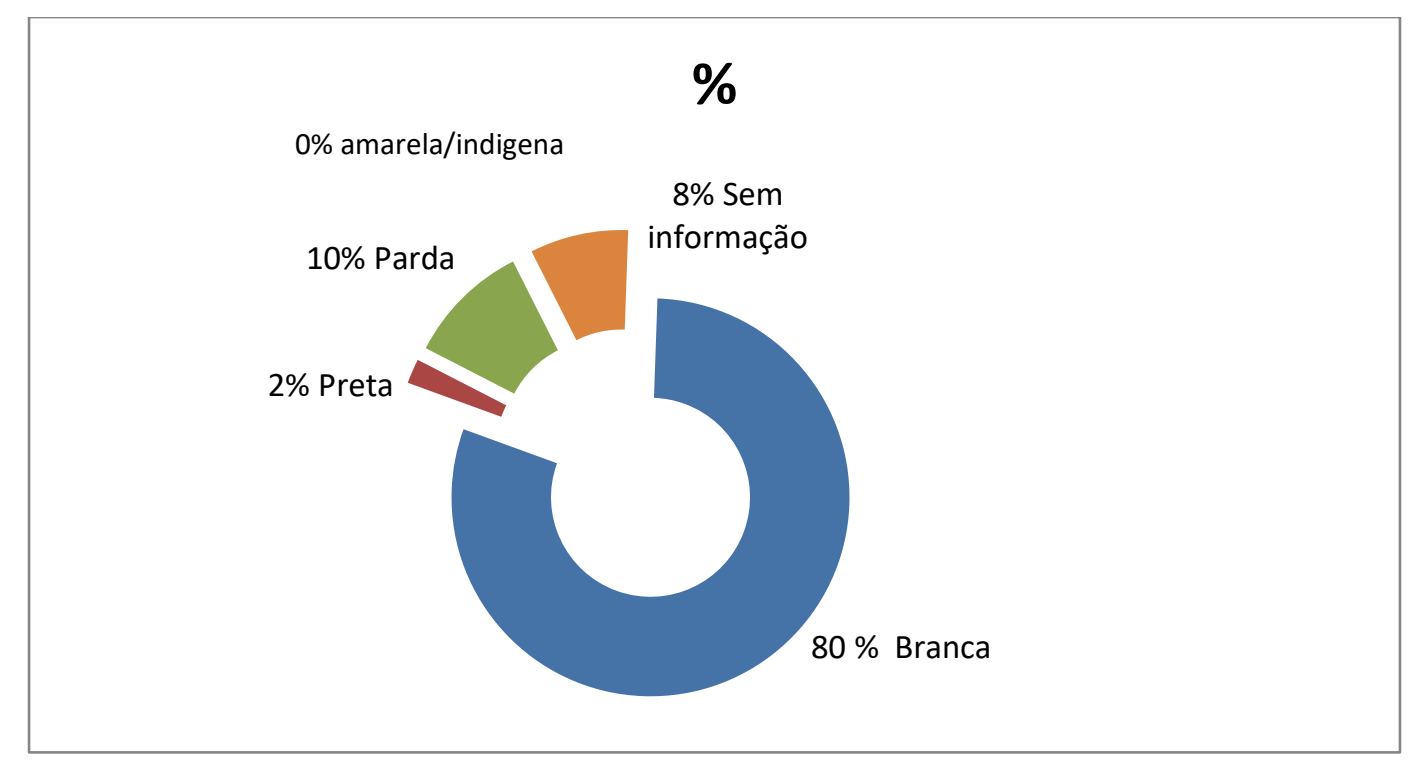

Fonte: Serviço de Atenção a Pessoas em Situação de Acumulação da Vigilância Ambiental Lapa/Pinheiros 
A figura 2 elenca a distribuição da ocupação / forma de sustento, dos casos de TA, independente do sexo e idade. Verifica-se que parcela considerável dos casos $(46,0 \%)$ se encontra na categoria dos aposentados e pensionistas, sendo que $54 \%$ estão distribuídos em diversas ocupações

Figura 2 - Distribuição percentual dos casos de transtorno da acumulação na Subprefeitura regional da Lapa e da Subprefeitura regional de Pinheiros, do município de São Paulo, entre 2016 e 2019, segundo a ocupação e /ou forma de sustento

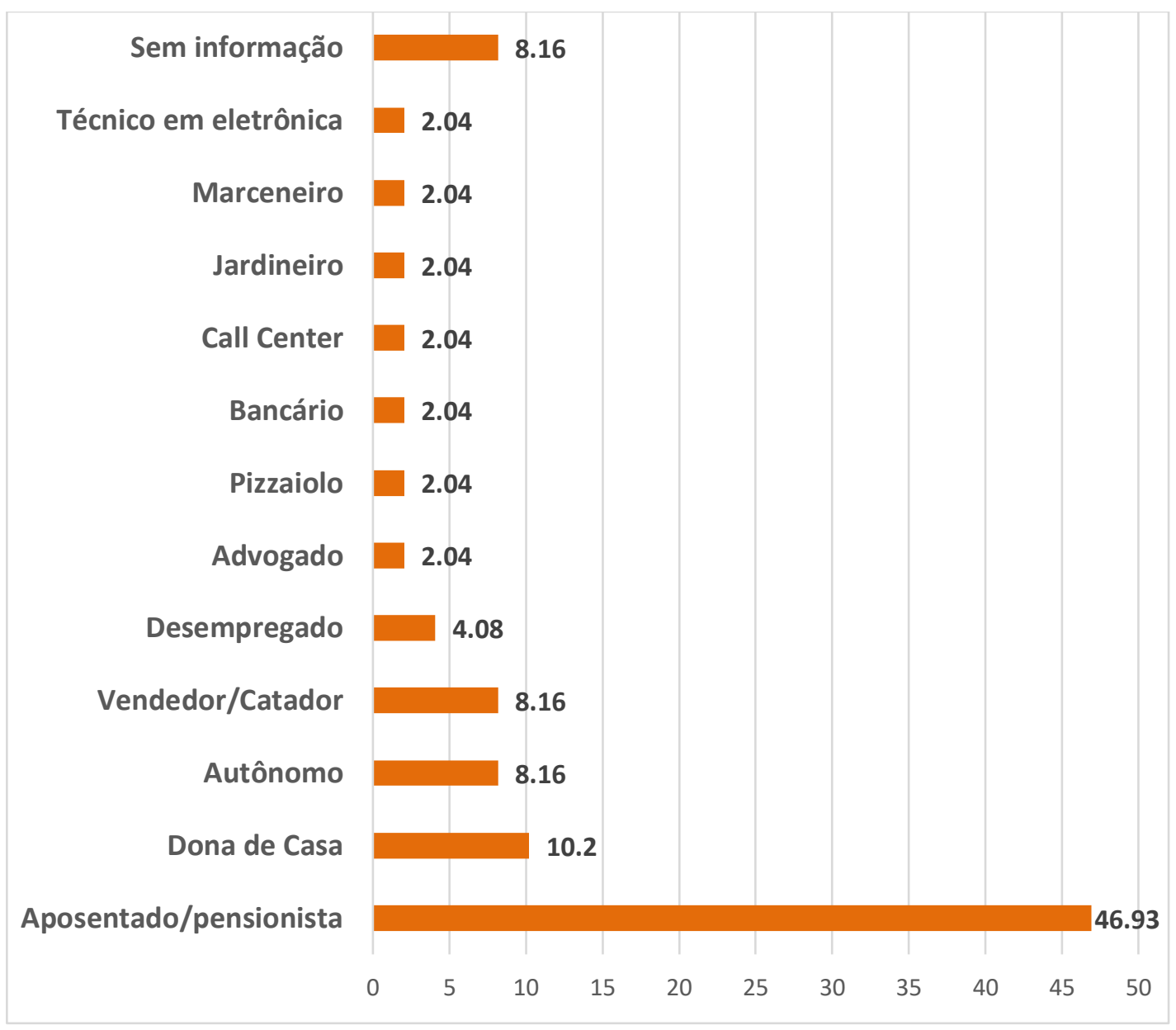

Fonte: Serviço de Atenção a Pessoas em Situação de Acumulação da Vigilância Ambiental Lapa/Pinheiros

A figura 3 expõe, os acometidos pelo TA, segundo o tipo de moradia mostrando que a grande maioria dos casos $(86,0 \%)$ habita em imóvel próprio. 
Figura 3 - Distribuição dos casos de Transtorno da Acumulação, na Subprefeitura Regional da Lapa e na Subprefeitura de Pinheiros, do município de São Paulo, entre 2016 e 2019, segundo o tipo de moradia.

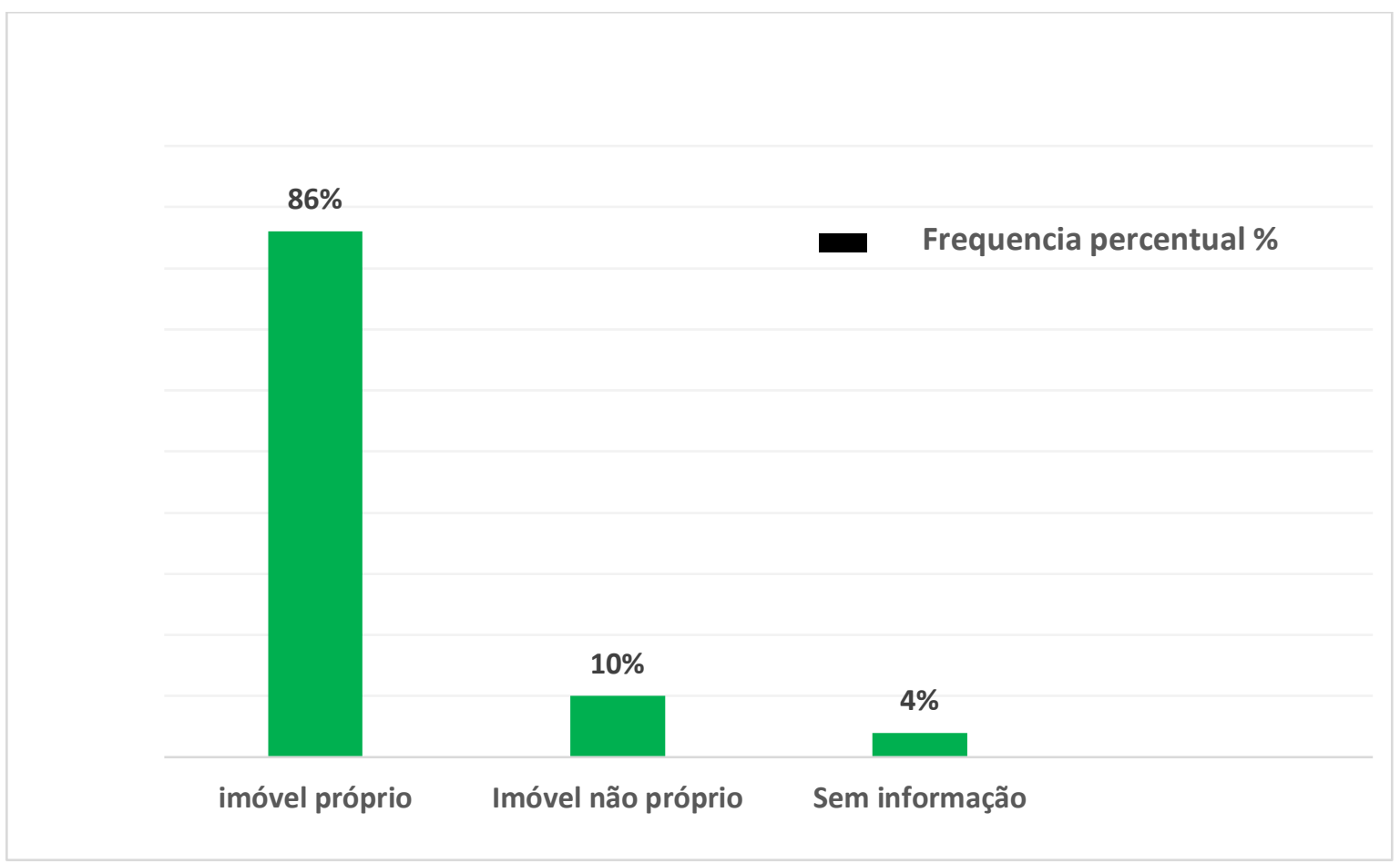

Fonte: Serviço de Atenção a Pessoas em Situação de Acumulação da Vigilância Ambiental Lapa/Pinheiros

Na tabela I é apresentada a distribuição dos acometidos por esse transtorno, segundo a faixa etária e o sexo. Temos 33 indivíduos, com idade acima de 6o anos, que representa $67,44 \%$ dos casos, independente do sexo, e entre 70-80 anos temos o intervalo etário com maior número de casos $(28,57 \%)$. Observa-se frequência discretamente maior, no sexo masculino (53\%) em relação ao sexo feminino (47\%).

A tabela expõe também uma tendência de maior idade entre os casos do sexo femininos e de idade menor, para os casos do sexo masculino. 
Tabela I - Distribuição dos casos de transtorno da acumulação na Subprefeitura regional da Lapa e na Subprefeitura regional de Pinheiros, do município de São Paulo, entre 2016 e 2019, quanto a faixa etária e sexo.

\begin{tabular}{|c|c|c|c|c|}
\hline Idade / sexo & Feminino & Masculino & Total & $\begin{array}{l}\text { Frequência } \\
\text { Percentual }\end{array}$ \\
\hline$<50$ anos & 4 & 5 & 9 & $18,36 \%$ \\
\hline $50-60$ anos & 2 & 5 & 7 & $14,20 \%$ \\
\hline $60-70$ anos & 6 & 3 & 9 & $18,36 \%$ \\
\hline $70-80$ anos & 5 & 9 & I4 & $28,57 \%$ \\
\hline$>80$ anos & 7 & I & 8 & $16,32 \%$ \\
\hline Sem Informação & I & I & 2 & $4,08 \%$ \\
\hline Total & $\begin{array}{c}24 \\
(47,0 \%)\end{array}$ & $\begin{array}{c}26 \\
(53,0 \%)\end{array}$ & $\begin{array}{c}49 \\
(\text { (100\%) }\end{array}$ & $100 \%$ \\
\hline
\end{tabular}

Fonte: Serviço de Atenção a Pessoas em Situação de Acumulação da Vigilância Ambiental Lapa/Pinheiros

A figura 4 mostra o tipo de material acumulado, pelos indivíduos, portadores do TA, na Lapa/Pinheiros mostrando que, 55\% dos casos tem preferência por diferentes tipos de objetos, seguido pelos que acumulam animais com 14,28\%. Há considerável diversidade de materiais acumulados pelos indivíduos como exposto na figura. 
Figura 4 - Distribuição em número absoluto e porcentagem dos casos do transtorno da acumulação na Subprefeitura regional da Lapa e na Subprefeitura regional de Pinheiros, do município de São Paulo entre 2016 e 2019, segundo tipo de material acumulado

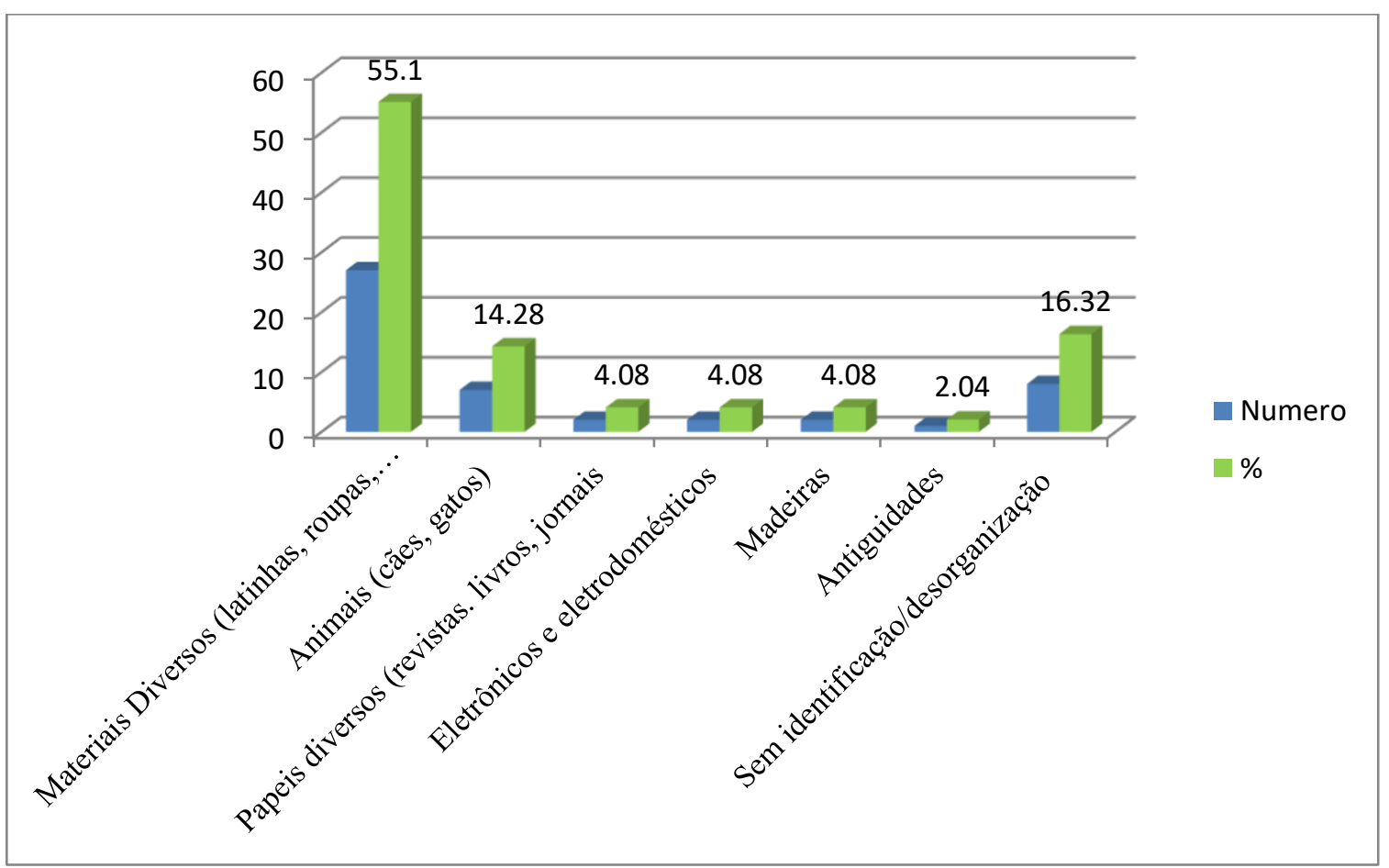

Fonte: Serviço de Atenção a Pessoas em Situação de Acumulação da Vigilância Ambiental Lapa/Pinheiros

O quadro I apresenta a distribuição dos acometidos pelo TA, segundo o distrito administrativo de residência, em números absolutos e a respectiva taxa de prevalência. A taxa de prevalência de TA na Subprefeitura Lapa se mostra maior Io,9 / Ioo.0oo habitantes (hab.) que a taxa de prevalência de TA na Subprefeitura de Pinheiros 4,7/10o.ooo hab. Entre os DA o maior coeficiente, ocorreu no DA Jaguara com 29,1/100.0oo habitantes (hab.), seguido pela Vila Leopoldina (15,6/100.00o hab.) e pelo Jaguaré (I4,6/10o.ooo hab.). Quando não desagregada a taxa de prevalência encontrado das Subprefeituras da Lapa e Pinheiros, foi de 7,9/10o.0oo habitantes, no período em estudo. 
Quadro I - Distribuição dos casos de Transtorno da Acumulação por Distrito Administrativo de residência, os respectivos Coeficientes de Prevalência de TA, na Subprefeitura regional da Lapa e na Subprefeitura de Pinheiros, do município de São Paulo, entre 2016 e 2019 .

\begin{tabular}{|c|c|c|c|c|c|}
\hline $\begin{array}{c}\text { Subp } \\
\text { refeit } \\
\text { ura }\end{array}$ & $\begin{array}{c}\text { Distrito } \\
\text { Administrativo } \\
\text { (DA) }\end{array}$ & $\begin{array}{l}\text { População } \\
\text { estimada(2or9- } \\
\text { SEADE) hab. }\end{array}$ & $\begin{array}{l}\text { Número } \\
\text { absoluto de } \\
\text { casos }\end{array}$ & $\begin{array}{c}\text { Porcentagem } \\
\text { de casos por } \\
\text { DA \% }\end{array}$ & $\begin{array}{c}\text { Taxa de } \\
\text { Prevalência } \\
\text { do TA por } \\
\text { DA }\end{array}$ \\
\hline \multirow{7}{*}{$\begin{array}{c}\text { Subp } \\
\text { refeit } \\
\text { ura } \\
\text { Lapa }\end{array}$} & Barra Funda & 15.927 & o & o & o \\
\hline & Jaguara & 24.042 & 7 & 14,28 & $29, \mathrm{I}$ \\
\hline & Jaguaré & 54.697 & 8 & 16,32 & I4,6 \\
\hline & Lapa & 67.118 & 6 & 12,24 & 8,9 \\
\hline & Perdizes & II 4.552 & 7 & 14,28 & $6, \mathrm{I}$ \\
\hline & Vila Leopoldina & 44.643 & 7 & 14,28 & 15,6 \\
\hline & Subtotal Lapa & 320.979 & 35 & 71,42 & 10,9 \\
\hline \multirow{3}{*}{$\begin{array}{l}\text { Subp } \\
\text { refeit }\end{array}$} & $\begin{array}{l}\text { Alto de } \\
\text { Pinheiros }\end{array}$ & 4I.I9I & 5 & I0,2 & $\mathrm{I} 2, \mathrm{I}$ \\
\hline & Itaim Bibi & 96.896 & 5 & 10,2 & 5,1 \\
\hline & Jardim Paulista & 90.588 & 2 & 4,08 & 2,2 \\
\hline \multirow{2}{*}{$\begin{array}{l}\text { Pinh } \\
\text { eiros }\end{array}$} & Pinheiros & 65.895 & 2 & 4,08 & 3 \\
\hline & $\begin{array}{l}\text { Subtotal } \\
\text { Pinheiros }\end{array}$ & 294.570 & 14 & 28,58 & 4,7 \\
\hline \multicolumn{2}{|c|}{ Total Lapa/Pinheiros } & 615.549 & 49 & 100 & 7,9 \\
\hline
\end{tabular}

Fonte: Serviço de Atenção a Pessoas em Situação de Acumulação da Vigilância Ambiental Lapa/Pinheiros

Coeficiente $($ Taxa) de Prevalência $\mathrm{TA}=\mathrm{n}$ o de casos de $\mathrm{TA} \times$ Ioo.ooo $/$ população do DA 
O quadro II mostra o número de ações e o volume de material acumulado recolhido, no período. Com o apoio institucional, a retirada de material acumulado se mostrou bem evidente.

Quadro II - Ações consentidas de retirada de material acumulado, dos casos do transtorno da acumulação na prefeitura da Lapa/Pinheiros, entre 2016 e 2019.

\begin{tabular}{|l|c|c|}
\hline Caracterização da atividade & $\begin{array}{c}\text { Ação com Apoio } \\
\text { Institucional (PMSP) }\end{array}$ & $\begin{array}{c}\text { Quantidade de material } \\
\text { vendido pelo acometido } \\
\text { pelo TA }\end{array}$ \\
\hline $\begin{array}{l}\text { Número de ações de } \\
\text { remoção do material } \\
\text { acumulado }\end{array}$ & 22 & $\ldots$ \\
\hline $\begin{array}{l}\text { Número de Caminhões } \\
\text { utilizados na remoção }\end{array}$ & $69^{*}$ & $\ldots$ \\
\hline \\
Quantidade em quilos
\end{tabular}

Fonte: Serviço de Atenção a Pessoas em Situação de Acumulação da Vigilância Ambiental Lapa/Pinheiros

- *Caminhão com capacidade de 9 metros $^{3}$.

- ** inclui ferro (2.89o quilos) plásticos (210 quilos) e outros materiais (50 quilos)

\section{DISCUSSÃO}

A maioria dos casos de TA, na Lapa / Pinheiros no período em estudo, ocorreu em indivíduos da raça branca $(80,0 \%)$, sendo apenas $10 \%$ em pardos e $2 \%$ em pretos (Figurar). Considerando que a população negra, que inclui pretos e pardos, no município de São Paulo representa $40 \%$ do total da população (IBGE,2010), o distúrbio parece afetar afrodescendentes e brancos de forma desproporcionada, no território em estudo, podendo traduzir um possível fator hereditário, ou a menor esperança de vida dos negros na sociedade brasileira como aponta o IBGE (2010), entre outros. Evidencia-se, portanto, a necessidade de observações futuras com esse recorte. 
Quanto ao rendimento, ou forma de sustento (Figura 2), 46,0\% dos casos se encontram na categoria dos aposentados e pensionistas - dado esperado - em virtude do agravo se destacar em idade superior a 60 anos. Vários casos possuem mais de uma fonte de renda e convém ressaltar a dificuldade na identificação desses rendimentos básicos, bem como outros aspectos nos acometidos em consequência do recolhimento, característico do agravo, ou pelo vínculo com a equipe em constante construção.

Na Figura 3, observa-se que 86,o \% dos casos analisados habitam em imóvel próprio. O censo demográfico de 2010 (IBGE,2010) mostrou uma porcentagem de imóveis próprios no Distrito de Pinheiros próximo de 72\%. Nesse quesito há certa proximidade percentual entre a população em geral e os acometidos.

Quanto à idade (Tabela I), verifica-se uma concentração de 63,25 \% dos casos, acima de 60 anos, independente do sexo, e tipo de acúmulo. A faixa etária com maior porcentagem de casos foi entre 7o-8o anos $28,36 \%$. A idade mínima encontrada foi de 34 anos, e a idade máxima de 96 anos, sendo respectivamente do sexo masculino e feminino. Discreta maioria dos casos do sexo masculino 53\%, apesar da maioria dos estudos indicarem as mulheres como as mais acometidas (ARAUJO, E.2015; GARGIULO,2019). A idade média encontrada, entre os casos, independentemente do sexo, foi de 59,82 anos.

Há um aumento mundial na prevalência do TA, considerando a elevação da expectativa de vida. Em 205o, segundo PASTERNAK (2014) a população acima dos 65 anos de idade, deve ultrapassar $22 \%$ da população, demandando planejamento das autoridades em saúde sobre esse segmento populacional.

A figura 4, mostra que os materiais acumulados, em sua maioria, são de diversos tipos $(69,38 \%)$, sendo infrequente o acúmulo de apenas um tipo de material por esses indivíduos. Diferentemente, os indivíduos que acumulam animais têm predileção por apenas uma espécie animal, sendo encontrado mais frequentemente em mulheres (ARAUJO, E.2015; GARCIA,2019; RODRIGUES,2019). O tipo de material acumulado relaciona-se com animais sinantrópicos que melhor se adaptam ao material. Em regiões endêmicas de leishmaniose visceral, por exemplo, existe maior risco de contrair a doença quando se observa acumulação, com cães e ou gatos, ocasionando um grave problema de saúde pública, visto que a doença entre os animais não tem cura e no homem pode ser letal (HENRIQUES,2019).

A taxa de prevalência (Quadro I) é uma probabilidade estatística de ocorrer um determinado evento em determinado tempo. A taxa de prevalência do transtorno na Lapa/Pinheiros foi de 7,9/10o.ooo hab. Quando desagregada, a taxa de prevalência na Lapa ficou em 10,9/10o.ooo hab. e em Pinheiros ficou em 4,7/10o.0oo hab. A presença de maior número de Unidades Básicas de Saúde com Estratégia da Saúde da Família, até 2019, na região da Lapa (o5 unidades), em comparação com a região de Pinheiros (or unidade), pode explicar as discrepâncias entre as taxas, considerando que os agentes comunitários de saúde conseguem identificar supostos portadores pelo 
TA de forma mais precoce no território. No DA Barra Funda não houve registro de pessoas portadoras da disfunção no período provavelmente, por se tratar de área pouco povoada e região prioritariamente comercial e industrial.

As ações de retirada de materiais (Quadro II), foram mais efetivas quando o apoio institucional foi ofertado aos indivíduos; como caminhões e pessoal para o transporte dos materiais. Quando deixado ao indivíduo a responsabilidade pela retirada do material acumulado há uma percepção de retardamento neste desfazimento e, aparente menor volume recolhido, inferindo uma relevância ao trabalho da rede de apoio e da equipe institucional que acompanha o acometido. Não houve aferição do peso do material retirado, nestas ações, mas 69 caminhões com capacidade de $9 \mathrm{~m}^{3}$ dá uma dimensão do volume que esses indivíduos conseguem acumular.

Não foi possível, neste levantamento, evidenciar outros atributos desse segmento populacional; como existência de sobrepeso, nível educacional, grau de insight, comorbidades associadas, antecedentes familiares, importantes na caracterização do agravo.

É necessário reafirmar que a retirada de objetos, sempre esteve acompanhada da anuência do indivíduo acometido pelo transtorno, geralmente após inúmeros acordos e convencimentos. É desejável que o mesmo esteja em tratamento de saúde local e especializada quando exigido, caso contrário tende ao fracasso e recaídas. A mitigação dos sentimentos de perda e dos riscos de agravamento da saúde física e emocional, geralmente já alterada, dos que sofrem com a intervenção deve sempre ser considerada.

Quando a situação de acumulação ocorre com animais, no município de São Paulo, são ofertados vacinação, "chipagem", Registro Geral do Animal (RGA), castração e estimulada a doação desses animais.

O lançamento da quinta edição do Manual Diagnóstico e Estatístico de Transtornos Mentais (DSM-5), ao incluir o Transtorno da Acumulação, abre caminhos preditivos aos diagnósticos, mas com risco ao fortalecimento de patologização e da medicalização da existência de "comportamentos dissonantes" socialmente.

Por outro lado, a disfunção traz custos importantes para a sociedade devido aos riscos à saúde e à segurança dos indivíduos, da coletividade e especialmente aos idosos. Com uma prevalência do agravo junto aos idosos significativa, há que se ter o cuidado de não fortalecer o etarismo já presente na sociedade atual.

\section{CONSIDERAÇÕES FINAIS}

Estrategicamente, a identificação do problema do TA pela atenção básica, pelos agentes comunitários de saúde e agentes de saúde ambiental/endemias 
oportuniza a abordagem e seguimento dos casos pela rede de atenção de forma mais precoce, reduzindo o agravamento dos acometidos.

O acompanhamento e apoio institucional, representado pela equipe do serviço de atenção a pessoas em situação de acumulação da Vigilância Ambiental Lapa/Pinheiros, e outros entes públicos, no recolhimento de material dos imóveis foi determinante no controle ambiental.

Estudos descritivos almejam a compreensão dos processos de saúde-doençacuidado, sugerem investigações em outros formatos epidemiológicos, fornecem maior visibilidade aos gestores, profissionais da área, explicita problemas de saúde pública e oportuniza intervenções mais estruturantes.

Reconhecimentos: A toda equipe da Unidade de Vigilância Ambiental Lapa/Pinheiros, pela colaboração, e particularmente aos agentes de saúde ambiental e endemias, na busca ativa de pessoas em possível situação de acumulação no território.

\section{REFERÊNCIAS}

ARAÚJO, Álvaro Cabral; NETO, Francisco Lotufo. A nova classificação americana para os transtornos mentais-o DSM-5. Revista brasileira de terapia comportamental e cognitiva, v. I6, n. I, p. 67-82, 2014 .

ARAUJO, Eliana Novaes Procopio; SANTOS, Vandymeire Gonçalves. Transtorno de acumulação compulsiva de idosos: Possibilidades de cuidados e questões de saúde pública. Revista Kairós: Gerontologia, v. 18, n. 4, p. 81-10o, 2015 .

ASSOCIAÇÃO Americana de Psiquiatria. Manual diagnóstico e estatístico de transtornos mentais. DSM 5 $5^{\mathrm{a}}$. ed. Porto Alegre:Artmed,2014.

BARNHILL, John W. Casos clínicos do DSM-5. Artmed Editora, 2015.

CASTIEL, Luis David; GUILAM, Maria Cristina Rodrigues; FERREIRA, Marcos Santos. Correndo o risco: uma introdução aos riscos em saúde. SciELO-Editora FIOCRUZ, 2010.

CORRÊA, João Gabriel Zerba et al. Um olhar sobre os acumuladores no território de São Miguel Paulista, no desafio de um trabalho multiprofissional intersetorial, visando à atenção integral. BIS, Bol. Inst. Saúde (Impr.), p. 91-94, 2016.

FUNDAÇÃO SEADE. Fundação Sistema Estadual de Análise de Dados. Página Institucional. Disponível em: < www.seade.gov.br>, acesso em: 13 dez..2019.

GARCIA, Rita de Cassia Maria; MALDONADO, Nestor Alberto Calderón; BRANDESPIM, Daniel Friguglietti. Medicina Veterinária do Coletivo: fundamentos e práticas, Secão2. Integrativa Vet, 2019. 
GARGIULO, M.S.; CICOLELLA, D.A.; NORMANN, K.A.S.; GARCIA, A.P.H. Identificação e Cuidados no Transtorno de Acumulação. Rev.Enferm. UFPE on line., Recife, II(I2):5028-36, dez. 2017. acesso em 19.dez.2019.

HENRIQUES, Lucia de Fátima et al. Acumuladores: uma revisão integrativa do potencial risco de disseminação de doenças transmitidas por vetores e outros animais nocivos à saúde. BIS, Bol. Inst. Saúde (Impr.), p. 125-138, 2019.

INSTITUTO DE PESQUISA ECONÔMICA APLICADA - IPEA. Página Institucional. Disponível em: < https:// www.ipea.gov.br>, acesso em 13, dez.2019.

IERVOLINO, Alessandra C. et al. Prevalence and heritability of compulsive hoarding: a twin study. American Journal of Psychiatry, v. I66, n. Io, p. I156-I16ı, 2009.

MARICELMA, R.M. Transtorno de Acumulação . Promotora de Justiça com atribuição na área da pessoa idosa e pessoa com deficiência no Estado de São Paulo e Mestre em Direito Constitucional pela PUC-SP. Disponível em 〈http://www.ampid.org.br/vi/transtorno-de-acumulacao-a-atencao-porprocessos-de-trabalhos-articulados $>$ acesso em i2.dez.2019.

PASTERNAK, Suzana; BÓGUS, Lucia Maria Machado. Habitação de aluguel no Brasil e em São Paulo. Caderno CRH, v. 27, n. 71, p. 235-254, 2014.

DE RESENDE, Marina Silveira; PONTES, Samira Paula; CALAZANS, Roberto. O DSM-V e suas implicações no processo de medicalização da existência. Psicologia em revista, v. 21, n. 3, p. 534-546, 2015 .

RODRIGUES, Claudio Manuel. Acumuladores de animais na perspectiva da promoção e da vigilância em saúde. ABCS health sci, p. 195-202, 2019.

SCHMIDT, Diego Rafael; DELLA MÉA, Cristina Pilla; WAGNER, Marcia Fortes. Transtorno da Acumulação: características clínicas e epidemiológicas. CES Psicología, v. 7, n. 2, p. 27-43, 2014. 